\title{
Losing the Dark: A Planetarium PSA about Light Pollution
}

\author{
Carolyn Collins Petersen ${ }^{1}$ and Constance Walker ${ }^{2}$ \\ ${ }^{1}$ Loch Ness Productions, P.O. Box 924, Nederland, CO 80466, USA, email: \\ carolyn@lochnessproductions.com \\ ${ }^{2}$ National Optical Astronomy Observatories, 950 N. Cherry Ave., Tucson, AZ 85719, USA, \\ email: cwalker@noao.edu
}

\begin{abstract}
Losing the Dark is a six-minute PSA video created for fulldome theaters by Loch Ness Productions, the International Dark Sky Association Education Committee headed by Dr. Constance Walker of the National Optical Astronomy Observatories, Dome3, Adler Planetarium, and Babak Tafreshi (The World at Night). It explains light pollution, its effects, and ways to implement "wise lighting" practices to mitigate light pollution. The show is also made in flatscreen HD format for classical planetariums, non-dome theaters, and for presentatons by IDA speakers.
\end{abstract}

Keywords. light pollution, planetarium show, wise lighting practices

\section{The Project}

Light pollution interferes with our ability to study the sky in visual wavelengths. Residents of many communities live under light-polluted skies, affecting their abilities to see the stars. Light pollution is also known to have impacts on health, safety, and energy costs. Organizations such as the International Dark-Sky Association (IDA) work to educate the public about ways to reduce wasteful lighting. The IDA Education Committee determined that planetariums and science centers are useful venues to teach members of the public about light pollution. Working with fulldome production company Loch Ness Productions and using visual materials from Adler Planetarium, NASA, and others, they have crafted a short "public service announcement" type presentation called Losing the Dark for planetarium theaters and other venues. Early in the production process, the group decided to make the show available not just for fulldome, but also in "flat screen" movie file format for "classic" planetarium theaters (those without fulldome video technology), educators and othersto use in public lectures and presentations. The show is produced in English and several other languages. The official premiere was at the International Astronomical Union meeting in Beijing, China in August, 2012.

\section{Thematic Points of the Show}

The points about the light pollution's threats to astronomy and its costs and health impacts were used to inform the script for Losing the Dark. In addition, we offer three simple "wise use" steps to help mitigate light pollution: turn off unwanted lights, use shielded lights, place lights only where they are needed.

Losing the Dark utilizes striking views of light pollution on Earth and from space to illustrate the main points. It provides planetarium professionals, educators and other outreach professionals a multimedia approach to inform the public about this important topic. The show will be available in early 2013 for download by any facility that wishes to use it. For more information on Losing the Dark, please visit www.lochnessproductions.com or www.darksky.org. 